\title{
KEPEMIMPINAN MUTU KEPALA SEKOLAH DALAM PENINGKATAN MUTU PENDIDIKAN
}

\author{
Endang He rawan ${ }^{1}$ \\ ${ }^{1}$ Dosen Manajemen Pendidikan \\ Fakultas Ilmu Pendidikan Universitas Pendidikan Indonesia \\ Email:endangherawan@upi.edu
}

\begin{abstract}
The headmaster of an educational leader has an important role in improving the quality. In line with the role that is so important given to schools, namely improving the quality of human resources, the school in carrying out its functions should be able to provide quality education services to the participants, because the leadership exercised by the principal should be oriented to the quality of leadership concerned .. primary on quality, so-called leadership qualities. Quality leaders hip is leadership that always wants something perfect or best. leadership quality is basically an effect process for quality improvement, where leaders try to influence Bahawan to do what is deemed important by the leader. Leadership that leads to quality includes three managerial functions, including planning, control, and improvement in quality. School principals are implementing quality leadership, will share the res ponsibility, continuous improvement, providing materials and tools are required of teachers and staff. In the leadership quality of each component involved in education is the leader, in which each person is res ponsible to eliminate the obstacles faced, which could hinder the successful implementation of the task.
\end{abstract}

Keywords: Leadership, Quality, School Management

\footnotetext{
${ }^{1}$ Endang Herawan, adalah dosen pada Jurusan Administrasi Pendidikan, FIP-UPI.
} 


\section{A.Pendahuluan}

\begin{abstract}
Sekolah merupakan lembaga pendidikan yang bertugas untuk menyelenggarakan pendidikan yang sesuai dengan kebijakan atau peraturan yang telah ditetapkan pemerintah. Sebaik apapun kebijakan yang telah ditetapkan oleh pemerintah, seperti terkait dengan kurikulum 2013, maka keberhasilan dari implementasi kurkulum tersebut amat tergantung dari kesungguhan sekolah dalam mengimplementasikannya, dan kesungguhan itu akan terwujud tidak bisa dipisahkan dengan peranan kepala sekolah sebagai pimpinan.
\end{abstract}

Dalam pengelolaan sekolah, kepala sekolah sebagai manajer dan pemimpin pendidikan, bertugas untuk melaksanakan tugas-tugas administratif serta memberdayakan sumber daya yang ada di sekolah. Tugas-tugas adminsitratif yang harus dilakukan oleh manajer pendidikan, seperti kepala sekolah, cukup komplek, mulai dari merencanakan, melaksanakan dan mengawasi kegiatan-kegiatan sekolah, agar berjalan sesuai dengan rencana dan program yang telah ditetapkan $\begin{array}{ccr}\text { Sekolah sebagai } & \text { satuan } \\ \text { pendidikan yang } & \text { berfungsi } & \text { dalam } \\ \text { menyelenggarakan pendidikan } & \text { dalam } \\ \text { kegiatannya tidak } & \text { sekedar } & \text { asal }\end{array}$ berjalan, tetapi harus dapat memenuhi harapan pelanggan atau pemangku kepentingan, baik itu murid, orang tua, pengguna lulusan maupun pemerintah, dengan kata lain aspek kualitas hendaknya menjadi perhatian utama sekolah. Apalagi sekolah dewasa ini diberikan peranan strategis sebagai lembaga yang berfungsi menyiapkan sumber daya manusia yang berkulitas, yaitu yang berkarakter, cerdas, mandiri, dan kompetitif. Untuk mewujudkan pendidikan yang berkualitas, kepemimpinan pendidikan memegang peranan yang penting, pemimpin hendaknya mampu menyusun rencana dan program yang berkualitas, melaksanakannya secara konsisten serta melakukan pengawasan dengan baik, karena itu dalam melaksanakan fungsi kepemimpina, setiap pemimpin pendidikan seperti kepala sekolah hendaknya melaksanakan kepemimpinan mutu. Yaitu pemimpin yang memiliki visi, misi, memiliki inisiatif, memberikan inspirasi dan menunjukkan komitmennya terhadap kualitas, keterbukaan dalam komunikasi, mengembangan kerja tim, mengerti butuhan dan harapan pelanggan, serta melakukan perbaikan berkelanjutan.

\section{B. Pentingnya Kepemimpinan mutu Kepala Sekolah}

Terwujudnya pendidikan yang berkualitas tidak bisa dipisahkan dengan upaya yang dilakukan oleh kepala sekolah sebagai pemimpin. Banyak hasil riset dan pendapat yang dikemukakan oleh para ahli yang menyatakan ada keterkaitan antara peningkatan mutu pendidikan dengan kepemimpinan kepala sekolah, ini menunjukkan begitu pentingnya fungsi kepemimpinan yang dilakukan oleh kepala sekolah, seperti dikemukakan Richard Gordon (2007) yang menyatakan: bahwa dalam literatur profesional tentang administrasi ditekankan bahwa tanggung jawab utama administrator sekolah adalah sebagai pemimpin. Umumnya mereka sependapat bahwa kepemimpinan diperlukan untuk memperbaiki kinerja sekolah. Demikian juga menurut Mulyasa (2012) bahwa: Kepemimpinan pendidikan merupakan hal yang sangat 
penting dalam membangun sekolah efektif, hal yang sama dikemukakan Wahjosumijo (2013): Kepemimpinan adalah suatu kekuatan penting dalam pengelolaan, oleh sebab itu kemampuan memimpin secara efektif merupakan kunci untuk menjadi seseorang manajer yang efektif. Pandangan yang sama dikemukakan oleh Husaini Usman (2012): Pentingnya keberadaan kepemimpinana mutu untuk melaksanakan peningkatan mutu tidak dapat diabaikan. Tanpa kepemimpinan yang bermutu sulit untuk meningkatkana mutu. Prasyarat untuk meningkatkan mutu adalah kepemimpinan yang bermutu.

\section{Kepemimpinan Mutu Kepala Sekolah}

Sebagaimana dikemukkan di atas, kepemimpinan kepala sekolah merupakan salah satu aspek yang penting dan menjadi nilai kunci dalam mewujudkan pendidikan yang kualitas. Tanpa kepemimpinan kepala sekolah, maka proses peningkatan kualitas tidak dapat dilakukan secara rutin, karena untuk meningkatkan mutu perlu adanya komitmen pimpinan terhadap mutu, upaya mempengaruhi dan menggerakkan personil agar bekerja dengan baik serta memberdayakan sumber daya yang ada disekolah untuk selalu melakukan perbaikan secara berkelanjutan sehingga para pelanggan puas terhadap layanan yang diberikan sekolah.

Kepemimpinan yang menaruh perhatian utama pada kualitas, disebut kepemimpinan kualitas. Husaini Usman (2012) mengemukakan: kepemimpinan mutu ialah kepemimpinan yang selalu ingin sesuatu yang sempurna atau terbaik.
Pandangan lain dikemukakan Gaspert (2005) bahwa kepemimpinan kualitas pada dasarnya merupakan suatu proses pengaruh untuk perbaikan kualitas, di mana pemimpin mencoba mempengaruhi bahawan untuk melakukan apa yang dipandang penting oleh si pemimpin.

Seorang pemimpin yang melaksanakan kepemimpinan mutu akan berusaha untuk meningkatkan kinerja setiap personil dan sumber daya organisasi lainnya, seperti: alat atau mesin, dana, prosedur kerja sehingga terjadi peningkatan produktivitas kerja individu maupun lembaga. Dengan terwujunya produktivitas kerja ini dapat melahirkan kebanggaan bagi setiap personil. Menurut Nanang Fattah dan Mohammad Ali (2007)Dalam menjalankan fungsi kepemimpinan mutu, pemimpin pendidikan harus dapat membantu menciptakan iklim sosial yang baik sehingga dapat tercipta suasana persaudaraan serta kerja sama yang penuh rasa kebebasan, seperti (1) membantu kelompok mengorganisasikan diri. (2) membantu kelompok dalam menetapkan prosedur kerja dan (3) bertanggung jawab dalam pengambilan keputusan dengan kelompok.

Kepemimpinan mutu dalam suatu organisasi tidak terwujud dengan begitu saja, tetapi perlu adanya usaha dan komitmen dari pimpinan untuk mewujudkan lembaga yang bermutu serta dukungan yang positif dari semua staf yang terlibat dalam kegiatan tersebut untuk melaksanakan tugas dengan baik, melakukan perbaikan berkelanjutan, bekerja sama dan berupaya meningkatkan kemampuannya. Menurut Oakland (dalam Dorothea, 2002:106) ada 10 
elemen proses dalam mewujudkan kepemimpinan kualitas, antara lain:

1. Mendemonstrasikan kepemimpinan, yang meliputi tindakan untuk mengambil inisiatif, memberikan contoh yang baik, memimpin para bawahan atau pengikut dan memberikan inspirasi bagi rekan-rekannya, dan menunjukkan komitmennya terhadap kualitas.

2. Membangun kesadaran, yang meliputi pendidikan secara mandiri pada proses kepemimpinan kualitas, mendikusikan kepemimpinan kualitas, dan membantu para pengikut menjadi lebih sadar terhadap kualitas

3. Keterbukaan lini komunikasi, yang meliputi komunikasi vertical dan horizontal, komunikasi secara bebas dan terbuka, kepercayaan dan saling menanggapi, mau mendengar, memberikan informasi secara terbuka pada semua orang.

4. Menciptakan dorongan untuk mencapai tujuan, yang meliputi pendefinisian visi dan misi, menyusun tujuan dan sasaran yang relevan yang disusun oleh seluruh personil, dan menggunakan pandangan jangka panjang.

5. Fokus pada pelanggan, mengerti kebutuhan pelanggan, harapan, dan persyaratan pelanggan, mengetahui kepuasan pelanggan, mau mendengarkan pelanggan, dan melibatkan pelanggan dalam perencanaan dan pembuatan keputusan.

6. Pengembangan kerja tim
7. Memberikan dukungan, pelatihan, dan pendidikan

8. Membangun tanggapan dan kepercayaan

9. Menciptakan lingkungan yang mempromosikan continuous improvement, yang meliputi memandang maalah sebagai kesempatan, melaksanakan perbaikan, menguji nilai kebijakan, praktek, dan prosedur dan menghilangkan rasa ketakutan.

10. Menggunakan tim yang melakanakan proses.

Jarome S.Arcaro (2006) menyatakan:" Seorang pemimpin mutu didefinisikan sebagai orang yang mengukur keberhasilannya dengan keberhasilan individu-invividu di dalam organisasi. Pemimpin mutu dalam pendidikan ditandai dengan kemampuannya untuk menggambarkan visi lembaga kepada para stafnya yang ada sekolah serta mengilhami para staf untuk mengambil langkah-langkah atau tindakan yang diperlukan guna mewujudkan visi tersebut.

Josep M.Juran (dalam Nasution,2001) menyatakan bahwa kepemimpinan yang mengarah pada kualitas meliputi tiga fungsi manajerial, yaitu perencanaan, pengendalian, dan perbaikan kualitas secara berkesinambungan. Dalam perencanaan ditujukan untuk mengidentifikasi pelanggan dan kebutuhannya, mengembangkan metode dan proses kerja agar menghasilkan produk yang berkualitas. Pengendalian diarahkan evaluasi kinerja, membandingkan kinerja aktual dengan tujuan dan melakukan tindakan perbaikan, sedangkan perbaikan kualitas, 
diarahkan upaya perbaikan terhadap insfrasstruktur, personil, metoda atau proses kerja yang dianggap belum baik. Sementara itu N.S. Sukmadinata (2006:14)":Untuk menerapkan program mutu dalam pendidikan diperlukan kepemimpinan yang berorientasi pada mutu". Kepemimpinan mutu berpegang pada prinsip-prinsip:

1. Dalam kepemimpinan mutu, seseorang mengukur keberhasialannya dari keberhasilan orang-orang dalam organisasi.

2. Tanggung jawab berbagi

3. Perbaikan berkelanjutan.

4. Dalam pyramid kepemimpinan mutu, majelis sekolah, pengawas dan administrator harus menyediakan bahan serta alat-alat yang dibutuhkan guru dan staf.

5. Peran guru dan staf. Semua orang dalam piramid kepemimpinan mutu adalah pemimpin.

6. Sebagai pemimpin mutu, tiap orang bertanggung jawab menghilangkan hambatan yang mencegah performansi yang tinggi.

7. Tiap orang ingin menjadi orang yang unggul.

Dalam implementasi kepemimpinan mutu, seorang pemimpin berusaha memperhatikan mutu, mulai dari merencanakan, dimana dalam merencanakan ia berusaha untuk memahami apa yang diharapkan oleh para pelanggannya, melakukan pengendalian dengan cermat dan terus melakukan perbaikan kinerja seiring dengan harapan dan keinginan pelanggan yang selalu berkembang. Mukhopadhay (2005) telah mengidentifikasi berbagai ciri pimpinan dalam kontek manajemen mutu, yaitu: manajemen yang senantiasa bergerak, focus pada pelanggan, otonomi, eksperimen, menanggulangi kegagalan, mendukung inovasi dan mengatasi resiko, menciptakan rasa kekeluargaan, rasa kebersamaan diantara orang tua, siswa dan para guru dan staf, sebagai suatu keseluruhan, irama, keinginan, intensitas, dan antuaisme: merupakan kualitas yang esensial dari seorang pimpinan.

Seorang kepala sekolah yang melaksanakan kepemimpinan mutu akan berbeda kinerjanya dengan melaksanakan kepemimpinan dengan pola-popa tradisional yang kurang memperhatikan kebutuhan pelanggan. Kepala sekolah yang melaksanakan kepemimpinan mutu akan selalu berusaha bekerja guna memuaskan para pelanggannya, melalui upaya peningkatan kinerja personil, memberdayakan sumber daya organisasi dan perbaikan berkesinambungan. Ross (dalam Nasution,2001) mengindentifikasi karakteristik kepemimpinan kualitas, antara lain:

1. Visible, Committed, dan Knowledgeable,

kepemimpinan yang fokus pada kualitas dan mengembangkan hubungan yang baik dengan karyawan, pelanggan dan pemasok.

2. Semangat misionaris, yaitu mempromosikan aspek kualitas di luar organisasi.

3. Target yang agresif, yaitu perbaikan yang bersifat inkremental

4. Strong driver, yaitu tujuan ditetapkan dengan jelas 
5. Komunikasi nilai-nilai, melakukan perubahan budaya kearah budaya kualitas

6. Organisasi, struktur organisasi yang dimiliki adalah struktur mendatar yang meungkinkan adanya wewenang yang lebih besar bagi tingkat yang lebih rendah

7. Kontak dengan pelanggan.

Didasarkan pada tugas dan tanggung jawab pemimpin dalam implementasi manajemen mutu, kepemimpinan merupakan hal yang esensial dalam manajemen mutu.Pemimpin harus memiliki visi dan dapat menterjemahkannya kedalam kebijakan dan tujuan khusus dengan dengan jelas. Peter dan Austin (dalam Sallis, 1993) memberikan pertimbangan spisifik dalam kepemimpinan pendidikan, bahwa pemimnpin pendidikan membutuhkan kualifikasi:

1. Visi dan symbol. Kepala sekolah harus mengkominikasikan nilai-nilai lembaga pada stafnya, siswa dan masyarakat luas.

2. 'Management by walking about' merupakan hal yang diperlukan oleh gaya kepemimpinan untuk setiap lembaga.

3. 'For the kids'. Dalam pendidikan konsep tersebut identik dengan "dekat pada pelenggan”. Hal ini untuk meyakinkan bahwa lembaga memiliki focus yang jelas pada pelenggan utamanya.

4. Otonomi, percobaan, dan dukungan pada kegagalan. Pemimpin pendidikan harus menganjurkan adanya inovasi pada stafnya dan menyiapkan segala sesuatu untuk mengantisipasi kemungkinan yang timbul.

5. Ciptakan perasaan "kekeluargaan". Pemimpin perlu menciptakan rasa kekeluargaan dan dan memasyarakatkan pada siswa, orang tua, guru dan staf pendukung

6. Rasa kesatuan, irama, keinginan, intensitas dan antusias. Hal tersebut merupakan kualitas personal yang diperlukan oleh pimpinan pendidikan.

\section{Model Kepe mimpinan Mutu}

Dalam manajemen mutu dikenal salah satu pendekatan dalam kepemimpinan mutu, yaitu kepemimpinan transformasional. Menurut Gaspert (2005) Model kepemimpinan ini sesuai dengan tuntutan manajemen mutu, karena dalam implementasinya menuntut tanggung jawab bersama dan pemberdayaan, hal ini terakomodasi dalam model kepemimpinan tranformasional. Menurut Burns (dalam Aan dan Cepi,2004) menjelaskan kepemimpinan tranformasional sebagai proses yang pada dasarnya" para pemimpinan dan pengikut saling menaikan diri ketingkat moralitas dan motivasi yang lebih tinggi. Dalam Kepemimpinan transformasional, pemimpin akan berusaha mengubah seluruh organisasi dengan mentranformasikan organisasi menuju pandangan apa yang harus dilakukan organisasi dan bagaimana seharusnya organisasi itu berjalan dalam menuju sasaran kualitas yang telah ditetapkan, karena itu dalam kepemimpinan transformasional, pemimpinan selain memperhatikan kinerja organisasi, juga 
memperhatikan aspek manusiawi personil yang terlibat, seperti kemerdekaan, keadilan dan kemanusiaan.

Pemimpin tranformasional adalah seorang pemimpinan yang memiliki pandangan bukan saja untuk merespoon kepentinggan saat ini maupun masa yang akan datang. Menurut Covey dan Peters (dalam Aan dan Cepi, 2004), seorang pemimpin transformasional memiliki visi yang jelas, memiliki gambaran holistis tentang bagaimana organisasi di masa depan ketika semua tujuan dan sasarannya telah tercpai. Dengan demikian kepemimpinan trasnformasional dapat memberikan pengaruh yang kuat dalam penyusunan rencana strategis untuk mutu yang didalamnya mengandung arah dari

tujuan perbaikan mutu yang dilakukan terus-menerus, serta membuat keputusan yang efektif berkenaan dengan perbaikan mutu yang dilakukan secara terus-menerus guna meningkatkan kinerja organisasi, sehingga layanan yang diberikan dapat memuaskan pelanggan internal dan eksternal.

Jarome S.Arcaro $\begin{array}{r}\text { (2006) } \\ \text { konsep }\end{array}$
mengembangkan
kepemimpinan mutu mengacu pada
konsep tanggung jawab bersama
antara pimpinan dengan yang
dipimpin dan pemberdayaan personil
yang telibat dalam penyelenggaraan
pendidikan di sekolah, dan ia
memvisualisasikan gagasannya dalam
bentuk Piramida Kepemimpinan
Mutu, di bawa ini

\section{Kepemimpinan}

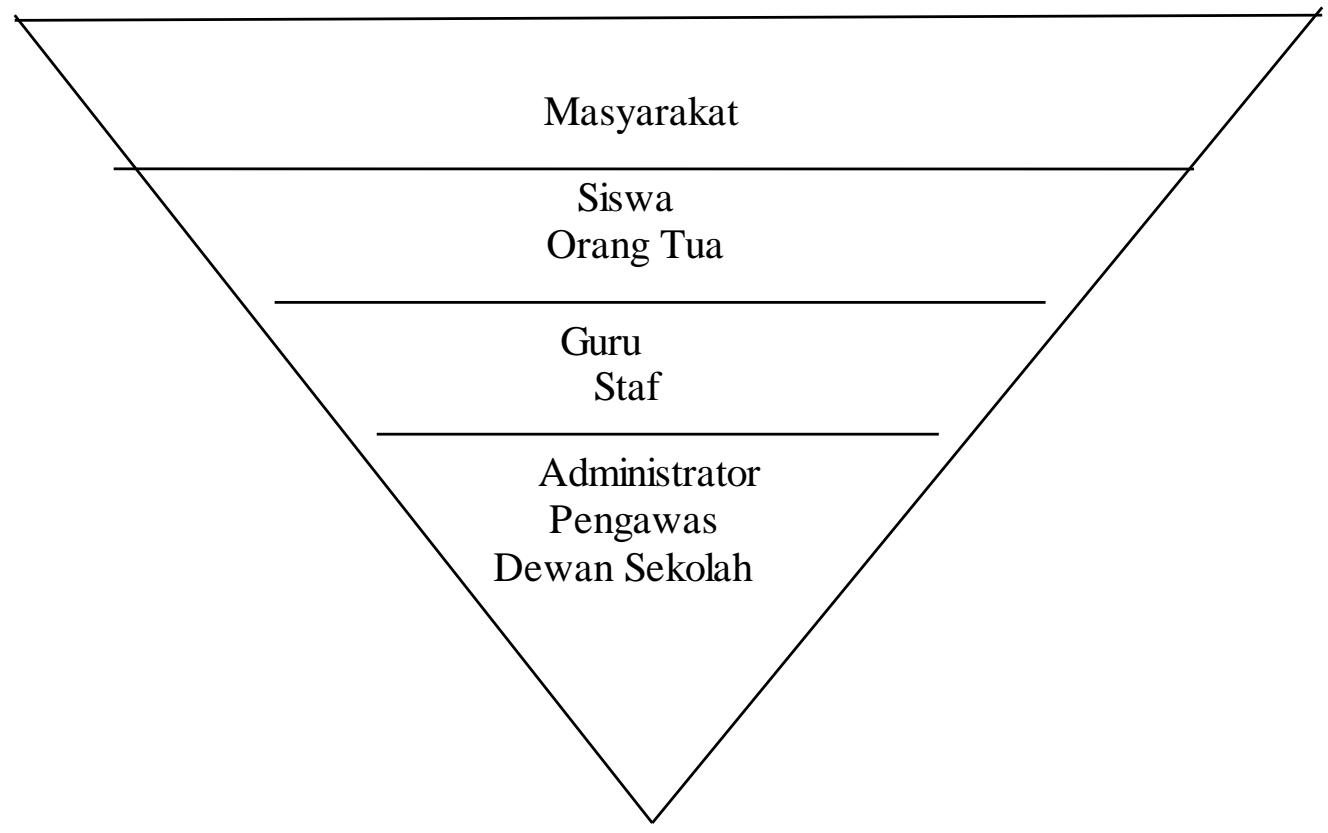

\section{Piramida Kepemimpinan Mutu (Jarome S.Arcaro,2006)}

Lebih lanjut Arcaro (2006) mengemukakan, dalam piramida kepemimpinan mutu ini setiap orang adalah pimpinan. Karena itu ia bertanggung jawab dalam masalah mutu. Pemimpin mutu yang 
mencerahkan dan mendorong para stafnya untuk mencapai tujuan utama organisasi.Dalam piramida kepemimpinan mutu, dewan sekolah, pengawas dan administrator harus memberikan kepada staf dan guru sejumlah sumber daya yang diperlukan untuk menunjang keberhasilannya.Dengan konsep kepemimpinan mutu seperti itu, ini berarti bahwa kekuasaan absolute yang selama ini melekat dan dimiliki dewan sekolah, pengawas dan administrator dalam mengelola lembaga tidak bisa dipertahankan lagi dalam mencapai visi mutu pendidikan. Namun ini tidak berarti dewan sekolah, pengawas dan administrator tidak memiliki kewenangan dalam mengambil keputusan yang menjadi wewenangnya berdasarkan pertaturan yang berlaku, serta merefleksikan kepedulian, pendapat, sikap dan kepentingan seluruh staf dan para pelanggannya.

Sebagai pemimpin mutu, bertanggung jawab untuk mewujudkan visi dengan melaksanakan tugas sesuai dengan tugas dan tanggung jawabnya. Dan tiap orang bertanggung jawab menghilangkah kendala pencapaian kinerja yang tinggi. Berkenaan dengan pernan guru untuk mewujudkan visi sekolah, seorang guru sebagai orang yang berhubungan langsung dengan pelanggan utama, yaitu siswa, guru mesti mengajak siswanya untuk memandang dirinya sebagai pemilik visi dan mesti berkeinginan untuk mendengarkan dan bertindak berdasarkan gagasan inovatif dan kreatif siswa dan guru dalam mancapai visi tersebut

\section{Daftar Bacaan}

Aan Komarial dan Cepi Triatna (2004) Visionary Leadership, Penerbit Bumi Aksara

Arcaro, Jerome S ( 2006) Pendidikan Berbasis Mutu (Edisi Terjemahan), Penerbit Pustaka Pelajar.

Gordon,Richard, Alson,Judy A, Snowden, Petra (2007) School Leadership And Administration, Mc Graw Hill

Husaini Usman (2013) Manajemen: Teori, Praktik dan Riset Pendidikan,

Penerbit Bumi Aksara

Mulyasa (2011) Manajemen dan Kepemimpinan Kepala Sekolah, Penerbit Bumi Akasara Jakarta.Press

Mukhopadhyay,Marmar (2005) Total Quality Management in Education, Sage

Publication.

Nasution,M.N (2001) Manajemen Mutu Terpadu, Penerbit Ghalia Indonesia

Nanang Fattah dan Mohammad Ali (2007) Manajememen Berbasis Sekolah, Penerbit UT

Nana Syaodih, Ayi Novi dan Ahman (2006) Pengendalian Mutu

Pendidikan Sekolah Menengah, Penerbit Refika Aditama

Sallis,Edward (1993) Total Quality Management in Education.London;Kogan

Page

Educational Series.

Spanbauer, Stanley (19920 A Quality System For Education, ASQC Quality 
Wahjosumijo (2013), Kepemimnan

Kepala Sekolah, Penerbit PT

RajaGrafindo

Persada

Vincent,Gasperst (2005).Total Qualiti

Management, Penerbit PT

Gramedia Pustaka

Utama 